\title{
The effect of early postnatal undernutrition on the growth and development of the rat brain
}

\author{
BY B. L. G. MORGAN AND D. J. NAISMITH \\ Department of Nutrition, Queen Elizabeth College, University of London, W8 7 AH
}

(Received 27 July 1981-Accepted 2 December 1981)

\begin{abstract}
1. Rat pups were undernourished during the period of the brain growth-spurt by feeding their mothers a low-protein diet from the third day post partum.

2. The pups were killed on days $5,6,9,12,16,20$ and 24 post partum, and their brains were analysed for protein, DNA, glycosides and glycoproteins. The activities of four enzymes involved in neurotransmission, and in the synthesis of glycolipids and myelin were also measured. Results of the analyses were compared with those obtained for pups that were suckled by well-nourished dams.

3. The brains of the undernourished pups contained substantially less protein and DNA; gangliosides and glycoproteins were also reduced.

4. All four enzymes showed lower peak activities in the nutritionally deprived animals, and the attainment of peak activity was retarded by several days.

5. These results suggest that undernutrition imposed during the brain growth-spurt leads to a deficit in the glial cell population and thus in the capacity to form myelin, and reduced development of cellular processes.
\end{abstract}

It is generally agreed that maternal undernutrition can affect the growth and development of the brain of the offspring. The timing and duration of the dietary restrictions imposed have, however, varied greatly and, since there are striking differences not only in the pattern and rate of growth of the different regions of the brain (Dickerson et al. 1967; Fish \& Winick, 1969) but also of the different brain cell populations (Altman, 1966; Croskerry et al. 1973), interpretation of the results has been contentious.

Restriction of the maternal diet during pregnancy alone or throughout pregnancy and lactation has been shown to influence brain weight, and its content of protein and DNA (Zamenhof et al. 1968; Winick, 1969; Clark et al. 1973), and brain metabolism, as indicated by altered enzyme activities (Adlard \& Dobbing, 1971) and enhanced seizure susceptibility to electroconvulsive shock (Stern et al. 1974). Postnatal food restriction has been reported to affect the development of acetylcholinesterase (EC 3.1.1.7) activity (Sereni et al. 1966) and the processes of dendritic proliferation (Bass et al. 1970) and myelination (Dobbing, 1968).

In the rat, neuronal multiplication occurs mainly during the last week of gestation, and on the second day post partum the adult complement of neurons is normally attained (Dobbing, 1970; Dobbing \& Sands, 1973; Croskerry et al. 1973). In comparison, postnatal neurogenesis, beginning approximately the fourth day post partum, is quantitatively small, and appears to be restricted to the production of short-axoned microneurons, particularly in the cerebellar cortex and the hippocampus (Altman, 1966; Croskerry et al. 1973). The proliferation of glial cells is also postnatal, and occurs throughout the suckling period (Dobbing, 1964). The massive increase in glial cell numbers followed by the deposition of lipids in the myelin sheath formed by these cells, and the concurrent development of axons, dendrites and their synaptic interconnections represents the so-called brain growth-spurt. It is at this time that the brain appears to be most sensitive to the effects of undernutrition (Dobbing, 1972).

Lipids are the major constituents of myelin, and there is evidence that most of the sialoglycoproteins and gangliosides of brain are localized in dendritic and axonal membranes, and in the synapses (Svennerholm, 1964; Wiegandt, 1967; Dyson \& Jones, 1976). We 
Table 1. Composition $(\mathrm{g} / \mathrm{kg})$ of experimental diets

\begin{tabular}{lcc}
\hline Constituent & Control diet & Low-protein diet \\
\hline Casein & 250 & 100 \\
Maize starch & 537.5 & 689 \\
Groundnut oil & 150 & 150 \\
DL-methionine & $2 \cdot 5$ & $1 \cdot 0$ \\
Salt mixture* & 40 & 40 \\
Vitamin mixture $\dagger$ & 20 & 20 \\
\hline
\end{tabular}

* Salt mixture formulated after Bernhart \& Tomarelli (1966).

† Vitamin mixture as described by Naismith et al. (1969).

decided, therefore, to investigate the effects of undernutrition, imposed during the growth spurt, by chemical analysis and by measuring the activities of enzymes that are known to regulate lipid synthesis and metabolism in the brain. The enzymes chosen for study form part of two distinct glycolipid systems (Dekirmenjian \& Brunngraber, 1969). One system, concerned with cerebroside synthesis is located in the myelin sheath: UDP-galactosyltransferase (EC 2.4.1.47) is a key enzyme in this system. The other is found in the dendritic and synaptic membranes, and is responsible for the formation of gangliosides. UDP-glucosyltransferase ( $E C$ 2.4.1.52) is thought to be the rate-limiting enzyme in this process, and CMP-N-acetylneuraminic acid synthetase (CMP-NANA-synthetase) also participates in ganglioside synthesis. The fourth enzyme to be studied was sialidase (EC 3.2.1.18).

Glycosidically-bound sialic acid ( $\mathrm{N}$-acetylneuraminic acid) is found in large amounts, as a constituent of gangliosides and sialoglycoproteins, in the synaptic membranes of the rat brain. It is suggested that these compounds may act as specific binding sites for positively charged neurotransmitters (Weseman et al. 1971). The enzyme sialidase, located in the membranes, may, by releasing sialic acid, change the local density of negative charge, and thus the flow of cations and other agents involved in neurotransmission (Schengrund \& Rosenberg, 1970; Schengrund \& Nelson, 1975). Any change in the level of activity of sialidase could therefore impair normal brain function, and might account for the abnormal behaviour reported in nutritionally deprived animals (Stewart $e t$ al. 1975).

A series of measurements were made throughout the period of the brain growth-spurt in order to study the evolution of the chemical deficit, and thus to interpret the functional and behavioural changes observed in animals that have been undernourished in early postnatal life.

\section{EX PERIMEN T AL}

\section{Design}

Litter-mate pairs of rats of the Sprague-Dawley strain were reared on a standard laboratory diet, and were mated when their body-weight exceeded $200 \mathrm{~g}$. On the third day post partum forty-eight pairs were selected, their litters were reduced to eight pups, and they were randomly distributed into two matched groups and housed individually with their litters. The first group was then fed, ad lib., a semi-synthetic diet containing $250 \mathrm{~g}$ casein $/ \mathrm{kg}$ diet (see Table 1). For the second group, the casein content of the diet was reduced to $100 \mathrm{~g} / \mathrm{kg}$. The pups of six pairs of litter-mate dams were weighed, then killed by decapitation on days $5,6,9,12,16,20$ and 24 post partum; i.e. ninety-six pups were killed on each of these days. The brains were removed, freed from membranes, pooled as litters, weighed and analysed for protein, DNA, ganglioside N-acetylneuraminic acid (NANA) and glycoprotein NANA. The activities of the four enzymes were measured in the pooled samples of brain. 
Table 2. Effects of undernutrition on the weight and composition of rat brain at different ages

(Mean values with their standard errors for six litters of eight pups)

\begin{tabular}{|c|c|c|c|c|c|c|c|c|c|c|c|c|}
\hline \multirow[b]{3}{*}{ Age (d) } & \multicolumn{4}{|c|}{ Wt (g) } & \multicolumn{4}{|c|}{ Protein (mg) } & \multicolumn{4}{|c|}{ DNA (mg) } \\
\hline & \multicolumn{2}{|c|}{ Control } & \multicolumn{2}{|c|}{ Undernourished } & \multicolumn{2}{|c|}{ Control } & \multicolumn{2}{|c|}{ Undernourished } & \multicolumn{2}{|c|}{ Control } & \multicolumn{2}{|c|}{ Undernourished } \\
\hline & Mean & SE & Mean & SE & Mean & SE & Mean & SE & Mean & SE & Mean & SE \\
\hline 5 & 0.63 & 0.06 & 0.50 & 0.06 & $19 \cdot 1$ & 0.7 & $15 \cdot 9$ & $0.9^{*}$ & 0.44 & 0.02 & 0.35 & $0.02^{*}$ \\
\hline 6 & 0.73 & 0.04 & & $0.05^{*}$ & 25.4 & 1.6 & 16.6 & $0 \cdot 4^{* *}$ & 0.46 & 0.02 & 0.37 & $0.02^{*}$ \\
\hline 9 & 0.88 & 0.03 & 0.64 & $0.03^{*}$ & $43 \cdot 0$ & $3 \cdot 3$ & $20 \cdot 0$ & $1 \cdot 8^{* *}$ & 0.56 & 0.04 & 0.46 & $0.02^{*}$ \\
\hline 12 & 0.97 & 0.04 & 0.73 & $0.05^{*}$ & $62 \cdot 8$ & $2 \cdot 4$ & $34 \cdot 7$ & $1 \cdot 5^{* *}$ & 0.67 & 0.02 & 0.55 & $0.02^{*}$ \\
\hline 16 & 1.32 & 0.03 & $1 \cdot 16$ & $0.04^{*}$ & $88 \cdot 5$ & $7 \cdot 8$ & $46 \cdot 3$ & $2 \cdot 5^{* *}$ & 0.88 & 0.03 & 0.75 & $0.03^{*}$ \\
\hline 20 & 1.46 & 0.02 & 1.22 & $0.03^{* *}$ & 97.6 & $7 \cdot 2$ & $51 \cdot 6$ & $3 \cdot 7 * *$ & 0.98 & 0.02 & 0.83 & $0.02^{*}$ \\
\hline 24 & 1.56 & 0.02 & 1.32 & $0.04 * *$ & 99.5 & $2 \cdot 2$ & $53 \cdot 7$ & $3 \cdot 3^{* *}$ & 0.96 & 0.03 & 0.82 & $0.02^{*}$ \\
\hline
\end{tabular}

Value differed significantly from control value; $* P<0.01,{ }^{* *} P<0.001$

\section{Analytical procedures}

Protein was determined by the method of Lowry et al. (1951). DNA was extracted from the tissues by the method of Klemperer (1963) and estimated by the diphenylamine reaction described by Burton (1956). Sialic acid (NANA) was determined by the thiobarbituric acid assay according to Warren (1959). Gangliosides and sialoglycoproteins were extracted from the tissues by the method of Suzuki (1965), and modified by Roukema \& Heijlman (1970), and estimated as NANA. UDP-galactosyltransferase and UDP-glucosyltransferase activities were measured by the procedures of Brenkert \& Radin (1972). CMP-NANA synthetase activity was estimated as described by Roukema et al. (1970). Sialidase activity was measured at $\mathrm{pH} 4.0$ using gangliosides as substrate, as reported by Roukema \& Heijlman (1970). For the chemical analyses, the pooled brains were homogenized in 9 vol. distilled water, freeze-dried, and stored at $-20^{\circ}$ in a desiccator until required. Enzyme assays were carried out on fresh material.

Student's $t$ test for related samples was used for the statistical evaluation of the results.

\section{RESULTS}

The low-protein diet that was fed during lactation has previously been shown to reduce milk production in the rat, and so retard growth of the offspring (Naismith, 1971). As expected, pups suckled by the undernourished dams were smaller, and had smaller brains. Mean body-weights of the control and undernourished pups on day 24 post partum were 65.6 and $35.8 \mathrm{~g}$ respectively. The results of the analyses of brain are shown in Table 2 . After only $3 \mathrm{~d}$ of feeding the low-protein diet (day 6) a significant difference was found between brain weights of the undernourished pups and those of their controls. This difference had increased further by day 9 but remained essentially constant thereafter. The analyses for protein and DNA showed a somewhat different picture. The deficit in both protein and DNA became progressively larger throughout the period of study. In both groups, the DNA content of the brain increased until day 20; no further increase occurred in the next $4 \mathrm{~d}$, when the brains of the undernourished animals contained $15 \%$ less DNA than those of the controls. Brain protein synthesis continued throughout the experimental period in both groups of animals, albeit at a decelerating rate after day 16 . In comparison with DNA, the suppression of protein synthesis brought about by food restriction was proportionately much greater, the difference in brain protein content at day 24 being $46 \%$. This differential 
Table 3. Effects of undernutrition on the composition of rat brain at different ages

(Mean values with their standard errors for six litters of eight pups)

\begin{tabular}{|c|c|c|c|c|c|c|c|c|c|c|c|c|}
\hline \multirow[b]{3}{*}{ Age (d) } & \multicolumn{4}{|c|}{ Protein:DNA } & \multicolumn{4}{|c|}{$\begin{array}{c}\text { Gangliosides } \\
(\mu \mathrm{mol} \text { NANA })\end{array}$} & \multicolumn{4}{|c|}{$\begin{array}{l}\text { Glycoproteins } \\
(\mu \mathrm{mol} \text { NANA })\end{array}$} \\
\hline & \multicolumn{2}{|c|}{ Control } & \multicolumn{2}{|c|}{ Undernourished } & \multicolumn{2}{|c|}{ Control } & \multicolumn{2}{|c|}{ Undernourished } & \multicolumn{2}{|c|}{ Control } & \multicolumn{2}{|c|}{ Undernourished } \\
\hline & Mean & SE & Mean & SE & Mean & SE & Mean & SE & Mean & SE & Mean & $\mathbf{S E}$ \\
\hline 5 & $44 \cdot 7$ & $1 \cdot 8$ & $45 \cdot 6$ & $2 \cdot 9$ & $0 \cdot 78$ & $0 \cdot 01$ & 0.66 & $0.02^{*}$ & $0 \cdot 34$ & $0 \cdot 01$ & $0 \cdot 24$ & $0.02^{*}$ \\
\hline 6 & 56.9 & $4 \cdot 6$ & $43 \cdot 1$ & $2 \cdot 0^{*}$ & 1.04 & 0.01 & 0.77 & $0.0 I^{* *}$ & 0.40 & 0.01 & 0.27 & $0.02^{*}$ \\
\hline 9 & $81 \cdot 3$ & 3.8 & $44 \cdot 4$ & $3 \cdot 5^{* *}$ & 1.96 & 0.02 & 1.43 & 0.01 & 0.68 & 0.02 & 0.44 & $0.01 * *$ \\
\hline 12 & 97.9 & 3.0 & $67 \cdot 4$ & $4 \cdot 1^{* *}$ & $2 \cdot 31$ & 0.03 & 1.96 & $0.02^{*}$ & 0.77 & 0.02 & 0.60 & $0.02^{*}$ \\
\hline 16 & $100 \cdot 6$ & $3 \cdot 4$ & $62 \cdot 0$ & $2 \cdot 5^{* *}$ & $2 \cdot 32$ & 0.01 & 2.05 & $0.01 * *$ & $1 \cdot 14$ & 0.01 & $0 \cdot 88$ & $0.01 * *$ \\
\hline 20 & $100 \cdot 0$ & 1.9 & $66 \cdot 0$ & $3 \cdot 9^{* *}$ & 3.61 & 0.02 & 3.01 & $0.02^{*}$ & $1 \cdot 38$ & 0.01 & 1.03 & $0.02^{*}$ \\
\hline 24 & $101 \cdot 2$ & $4 \cdot 6$ & $61 \cdot 4$ & $2 \cdot 6^{* *}$ & 3.97 & 0.02 & $3 \cdot 39$ & $0.02^{*}$ & 1.54 & 0.02 & $1 \cdot 15$ & $0.02^{*}$ \\
\hline
\end{tabular}

NANA, N-acetylneuraminic acid.

Value differed significantly from control value; ${ }^{*} P<0.01,{ }^{* *} P<0.001$.

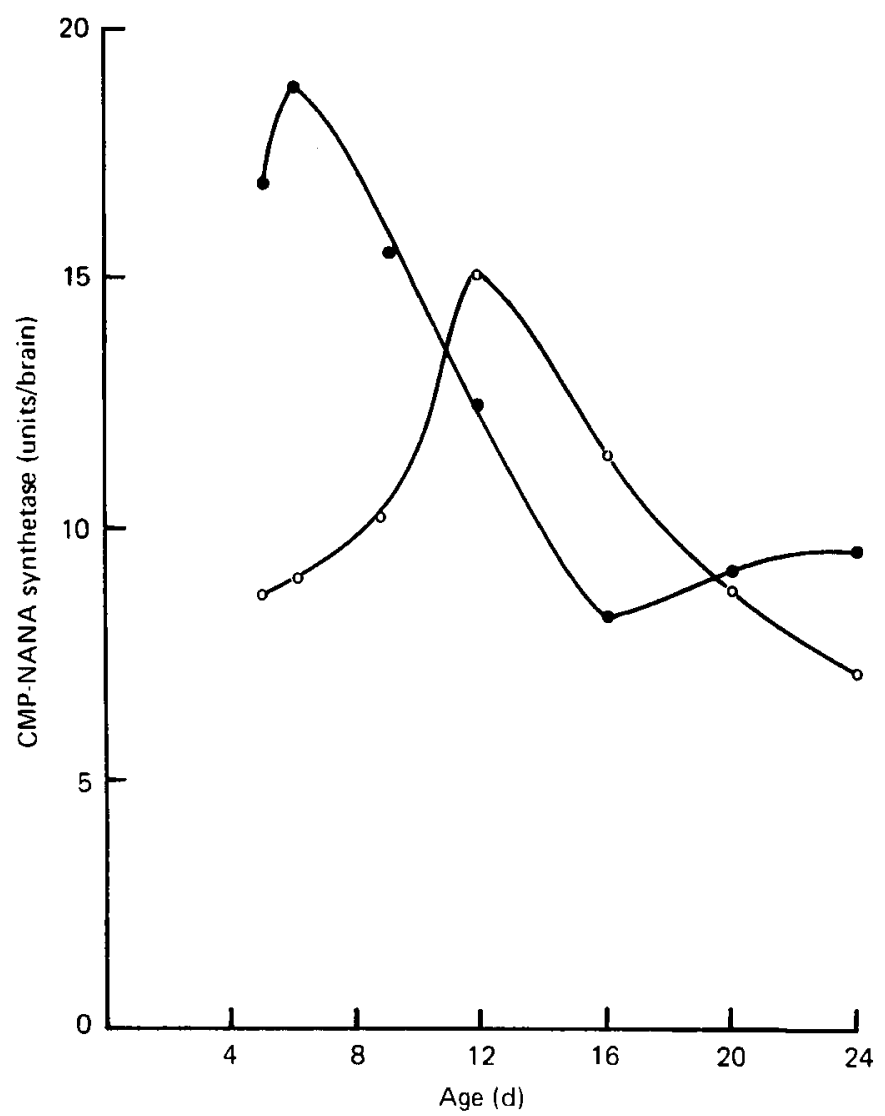

Fig. 1. Activity (units/brain) of CMP-N-acetylneuraminic acid synthetase (CMP-NANA synthetase) in the brains of well-fed $\left(O_{-}\right)$and undernourished $(\mathrm{O}-\mathrm{O})$ rat pups. Mean values for six litters of eight pups. One unit of activity is defined as $1 \mu \mathrm{mol}$ NANA utilized $/ \mathrm{h}$. For details of dietary treatment, see p. 16. 


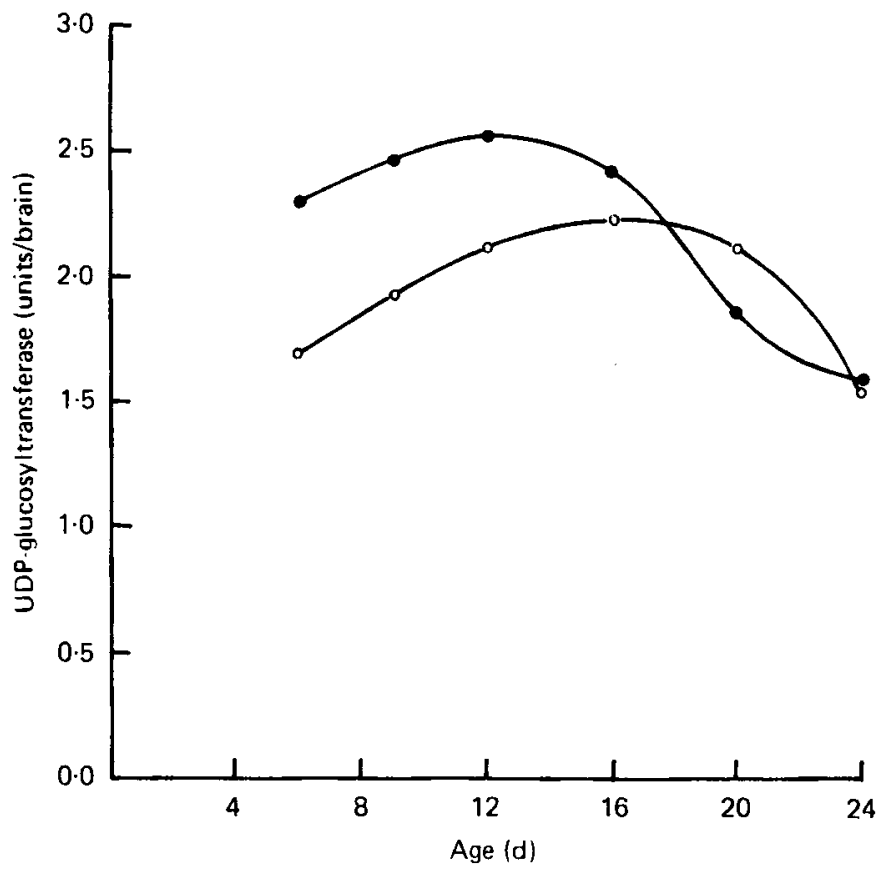

Fig. 2. Activity (units/brain) of UDP-glucosyltransferase (EC 2.4.1.52) in the brains of well-fed (- - ) and undernourished $(\mathrm{O}-\mathrm{O})$ rat pups. Mean values for six litters of eight pups. One unit of acitivity is defined as $1 \mathrm{nmol}$ cerebroside formed $/ \mathrm{h}$. For details of dietary treatment, see p. 16.

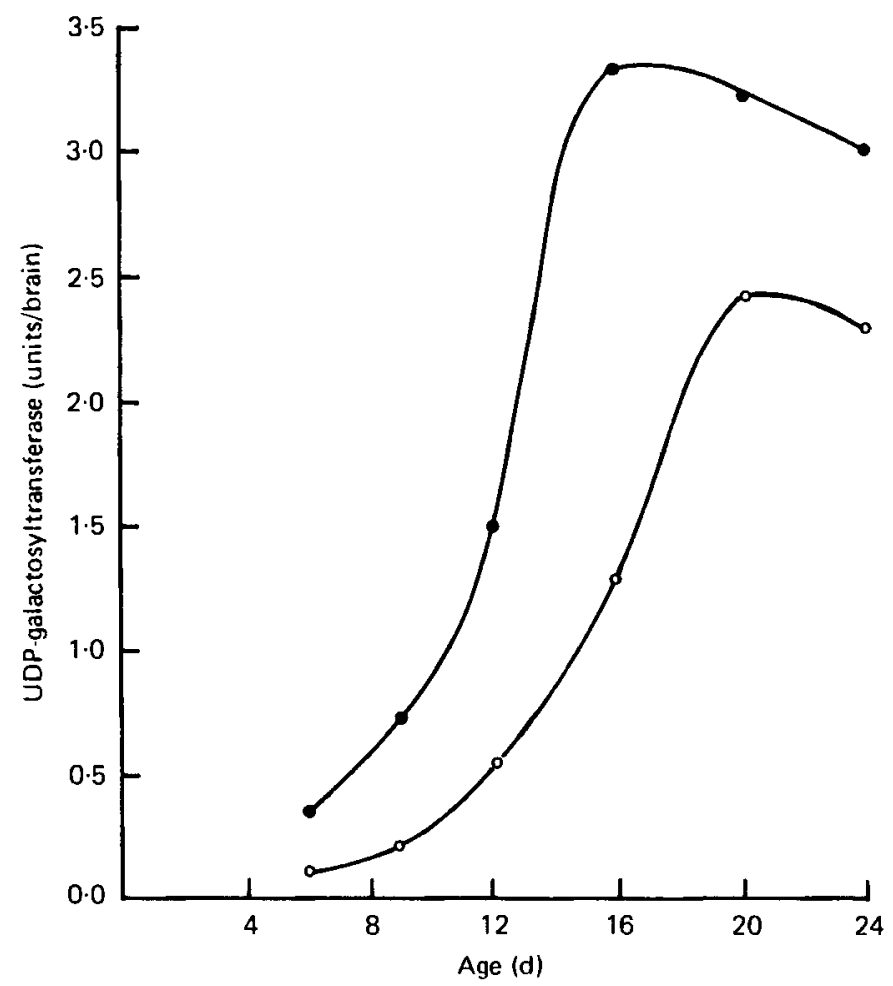

Fig. 3. Activity (units/brain) of UDP-galactosyltransferase (EC 2.4.1.47) brains of well-fed ( - $)$ and undernourished $\left(\mathrm{O}_{-}-\mathrm{O}\right)$ rat pups. Mean values for six litters of eight pups. One unit of activity is defined as $1 \mathrm{nmol}$ cerebroside formed $/ \mathrm{h}$. For details of dietary treatment, see p. 16. 


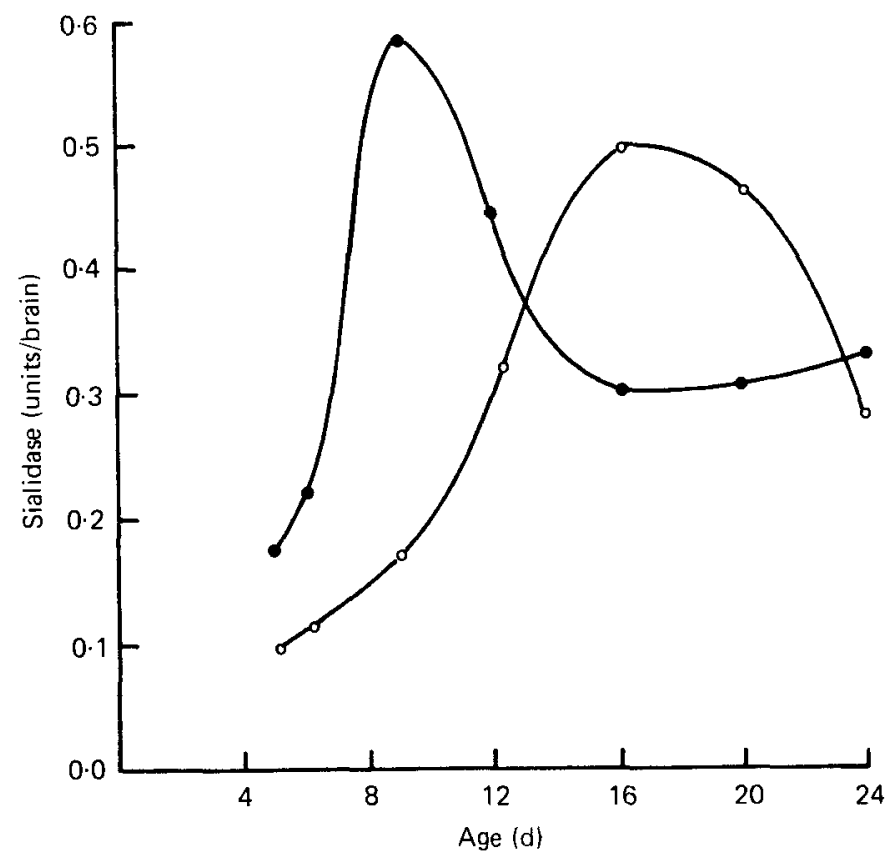

Fig. 4. Activity (units/brain) of sialidase ( $E C$ 3.2.1.18) in brains of well fed ( $-O)$ and undernourished $(\mathrm{O}-\mathrm{O})$ rat pups. Mean values for six litters of eight pups. One unit of activity is defined as $1 \mu \mathrm{mol}$ NANA released $/ \mathrm{h}$. For details of dietary treatment, see p. 16.

effect of undernutrition on the accretion of protein and DNA in the developing brain is shown clearly in the values for protein:DNA at different ages (Table 3).

The build-up of gangliosides in the brain followed the same pattern in the well-nourished and the undernourished pups; there was an initial rapid accumulation followed by a pause between days 12 and 16, then a second short period of synthetic activity which decreased rapidly before day 24 (Table 3). At all stages of ganglioside synthesis, however, the rate of accumulation was always less in the undernourished rats, and the final deficit amounted to $15 \%$. The results of the analyses for glycoproteins gave a similar picture, but in this instance maximum synthetic activity occurred between days 12 and 16 , and the fall in the rate of synthesis was more gradual. In the undernourished rats, the rate of increase in glycoproteins was depressed throughout the period of study, and consequently the brain content of glycoproteins was reduced by $25 \%$.

The enzymes CMP-NANA-synthetase and UDP-glucosyltransferase participate in ganglioside synthesis. The activity of CMP-NANA-synthetase measured in the well-fed control animals rose sharply until day 6 post partum (Fig. 1). There followed a decline in activity until day 16 , then a small rise to the stable mature level. In the undernourished pups, the attainment of peak activity was delayed by $6 \mathrm{~d}$. Furthermore, peak activity was considerably depressed, as was the final level of activity achieved. UDP-glucosyltransferase activity increased gradually between days 6 and 12, then decreased rapidly to level out at day 24 (Fig. 2). Once again, undernutrition delayed the attainment of peak activity, in this instance by $4 \mathrm{~d}$, and the shape of the curve suggested that the mature level of activity would be below that of the control animals. The development pattern of the transferase involved in cerebroside synthesis, UDP-galactosyltransferase, differed considerably from that of the enzymes already described (Fig. 3). A tenfold increase in activity was noted between days 
6 and 16, and a modest decrease thereafter. Analysis of the brains of the undernourished pups revealed reduced enzyme activity at all times, with maximum activity occurring $4 \mathrm{~d}$ later than in the controls.

The most striking effect of early postnatal undernutrition was seen on the enzyme sialidase (Fig. 4). In the control rat pup, there was a rapid increase in activity from a low level at day 5 to reach a maximum value at day 9 . The decrease in activity was almost as rapid, levelling out at day 16 . The activity profile obtained with the undernourished pups showed more gradual changes with age, and a displacement of at least $7 \mathrm{~d}$ in the timing of peak activity.

\section{DISCUSSION}

There are certain critical periods during the growth of the brain when metabolic changes resulting from undernutrition are believed to affect future development and function. Of these, the so-called brain growth-spurt, which begins when the adult complement of neurons has been achieved, is thought to be the most significant (Dobbing, 1970). At this time the neurons grow axons and dendrites, and form synaptic interconnections, and the process of myelination is initiated by a rapidly-expanding population of glial cells. The growth-spurt in the rat is an entirely postnatal phenomenon.

In the present experiment, the weights and composition of the brains of pups exposed to severe malnutrition throughout the period of the growth-spurt were compared with those of normal animals. During the first $24 \mathrm{~d}$ of postnatal life, brain weight was more than tripled in the well-nourished pups. On day 24 , however, the brains of the undernourished pups were found to be lighter, and to contain $15 \%$ less DNA and $46 \%$ less protein. The value for protein:DNA was therefore reduced, indicating that brain cells were smaller in size. Since both groups of pups had been nourished in utero and for the first $2 \mathrm{~d}$ after birth in precisely the same way, it may be assumed that their brains contained the same number of macro-neurons. The difference found in brain DNA content must therefore represent predominantly a difference in the glial cell complement, and consequently a reduced capacity to form myelin. As the myelin sheath provides the essential insulation for the propagation of nerve impulses along the axon, it is likely that neurotransmission, and hence behaviour, would be adversely affected in these animals. Bass et al. (1970) reported a delay in behavioural maturation in undernourished rat pups in which chemical evidence of reduced myelin formation was found. In a histological examination of the brains they also noted a decrease in dendritic proliferation and in the formation of synapses, when compared with normal animals. These differences might also account for abnormalities in behaviour.

In the present experiment, the large deficit in brain protein and reduced brain cell size suggests that the normal development of cellular processes, axons and dendrites, had been suppressed in the undernourised pups. This conclusion is supported by the results of the analyses for glycosides and glycoproteins. These complex lipids which are primarily located in the axonal dendritic and synaptic membranes were present in substantially reduced amounts in the brains of the undernourished pups. Likewise, Merat \& Dickerson (1973) postulated that the low levels of gangliosides found in postnatally undernourished rat pups were due to partial failure of dendritic development. Failure to achieve the normal growth of the nerve cellular processes could also affect brain function. Cragg (1972) has offered an explanation for the effects of early malnutrition on learning behaviour. He suggests that the number of synapses associated with each neuron determines the complexity of neuronal circuitry and hence, indirectly, governs mental performance.

The structural and biochemical changes occurring in the brain during the growth-spurt are too complex to allow a precise correlation between quantitative changes in brain glycolipids and the activities of enzymes that regulate their synthesis and metabolism. 
Nevertheless a study of the profiles of four of these enzymes in the brains of well-nourished and undernourished pups gave us some insight into the disturbances of brain development that account for the chemical deficit.

The developmental profiles of both UDP-glucosyltransferase and CMP-NANA-synthetase reported here for well-nourished pups agree well with previously published results (Brenkert \& Radin, 1972). The differences in enzyme activity between the two groups of animals suggest that the production of glycoproteins and gangliosides in the undernourished pups would be retarded and reduced in amount. Likewise the lower activity of UDPgalactosyltransferase found throughout the period of the growth-spurt and the delay in timing of peak activity in the undernourished animals would postpone the onset and reduce the extent of myelination. Our finding that appreciable UDP-galactosyltransferase activity appeared only after $9 \mathrm{~d}$ post partum confirms an earlier report (Brenkert \& Radin, 1972). The enzymes involved in the synthesis of myelin are found in brain in low concentrations until myelination begins on or close to the tenth day after birth.

The sialidase developmental profile showed a gradual increase in activity during days 5-9, followed by a rapid decrease to the mature level by day 16. Other workers using the chick as an experimental animal have also found very low levels of sialidase activity during the first few days of life. It has been suggested that this low activity ensures maximum local concentrations of gangliosides for ease of incorporation into the neuron cell membranes at this critical stage of development (Schengrund \& Rosenberg, 1971). Suzuki (1967) has also reported a slow turnover of gangliosides during the first $10 \mathrm{~d}$ of postnatal life in the rat. The delayed attainment of peak activity and the lower mature sialidase activity in our undernourished rats provides further evidence of disturbed maturation of the brain which might lead to impaired synaptic transmission.

The most striking finding that arose from the enzyme assays on the brains of the nutritionally deprived animals was the marked displacement in time of the attainment of peak activities, in one instance (sialidase) by $7 \mathrm{~d}$. The extent only, and not the timing, of the brain growth-spurt has been thought to be influenced by undernutrition (Dobbing, 1970). This may well be true for the multiplication of nerve cells, as measured by the rate of increment of DNA in the brain (Dobbing, 1972). Our observations suggest, however, that it may not be true for the growth of the cellular processes, and for the myelination of the neurons.

The authors gratefully acknowledge a research grant from the Gerber Company.

\section{REFERENCES}

Adlard, B. P. F. \& Dobbing, J. (1971). Brain Res. 28, 97.

Altman, J. (1966). J. Comp. Neurol. 128, 431.

Bass, N. H., Netsky, M. G. \& Young, E. (1970). Archs Neurol., Chicago 23, 289.

Bernhart, F. \& Tomarelli, R. (1966). J. Nutr. 89, 495.

Brenkert, A. \& Radin, N. S. (1972). Brain Res. 36, 183.

Burton, K. (1956). Biochem. J. 62, 315.

Clark, G. M., Zamenhof, S., Van Marthens, E., Grauel, L. \& Kruger, L. (1973). Brain Res. 54, 397.

Cragg, B. G. (1972). Brain 95, 143.

Croskerry, P. G., Smith, G. K., Shepard, B. J. \& Freeman, K. B. (1973). Brain Res. 52, 413.

Dekirmenjian, H. \& Brunngraber, E. G. (1969). Biochim. biophys. Acta 177, 1.

Dickerson, J. W. T., Dobbing, J. \& McCance, R. A. (1967). Proc. Roy. Soc. B. 166, 396.

Dobbing, J. (1964). Proc. Roy. Soc. B 159, 503.

Dobbing, J. (1968). In Applied Neurochemistry, p. 287 [A. N. Davison and J. Dobbing, editors]. Oxford: Blackwell. Dobbing, J. (1970). Am. J. Dis. Child. 120, 411.

Dobbing, J. (1972). Ciba Fdn Symp. no. 3, p. 9.

Dobbing, J. \& Sands, J. (1973). Archs Dis. Childh. 48, 757.

Dyson, S. E. \& Jones, D. G. (1976). Brain Res. 114, 365.

Fish, I. \& Winick, M. (1969). Exp. Neurol. 25, 534. 
Klemperer, G. (1963). In Methods of Biochemical Analysis, vol. 1, p. 287 [D. Glick, editor]. New York: Interscience Publishers Inc.

Lowry, O. H., Rosebrough, N. J., Farr, A. L. \& Randall, R. J. (1951). J. biol. Chem. 193, 265.

Merat, A. \& Dickerson, J. W. T. (1973). J. Neurochem. 20, 873.

Naismith, D. J. (1971). Proc. Nutr. Soc. 30, 93A.

Naismith, D. J., Akinyanju, P. A. \& Yudkin, J. (1969). J. Nutr. 97, 355.

Roukema, P. A. \& Heijlman, J. (1970). J. Neurochem. 17, 773.

Roukema, P. A., Van Den Eijnden, D. H., Heijlman, J. \& Van Der Berg, G. (1970). FEBS Lett. 9, 267.

Schengrund, C. L. \& Nelson, J. T. (1975). Biochem. Biophys. Res. Commun. 63, 217.

Schengrund, C. L. \& Rosenberg, A. (1970). J. biol. Chem. 245, 6196.

Schengrund, C. L. \& Rosenberg, A. (1971). Biochemistry, Easton 10, 2424.

Sereni, F., Principi, N., Perletti, L. \& Sereni, L. P. (1966). Biol. Neonate 10, 254.

Stern, W. C., Forbes, W. B., Resnick, O. \& Morgane, P. J. (1974). Brain Res. 79, 375.

Stewart, R. J. C., Preece, R. F. \& Sheppard, H. G. (1975). Br. J. Nutr. 33, 233.

Suzuki, K. (1965). J. Neurochem. 12, 969.

Suzuki, K. (1967). J. Neurochem. 14, 917.

Svennerholm, L. (1964). J. Neurochem. 11, 839.

Warren, L. (1959). J. biol. Chem. 234, 1971.

Weseman, W., Henkel, R. \& Marx, R. (1971). Biochem. Pharmac, 20, 1961.

Wiegandt, H. (1967). J. Neurochem. 14, 671.

Winick, M. (1969). J. Pediat., Springfield 74, 667.

Zamenhof, S., Van Marthens, E. \& Margolis, F. L. (1968). Science, N.Y. 160, 322. 